\title{
EDITORIAL
}

\section{More safety data: what about efficacy of sildenafil?}

\author{
Journal of Perinatology (2016) 36, 79; doi:10.1038/jp.2015.201
}

In this issue of the Journal of Perinatology, Samiee-Zafarghandy et al. report results of their multi-center retrospective study investigating the risk of severe retinopathy of prematurity in a large cohort of very low birth weight infants exposed to treatment with sildenafil. ${ }^{1}$ The authors matched 81 infants who received sildenafil with 243 non-exposed infants. Infants on sildenafil were born at a very low gestational age (median 25 weeks), and received more intensive care support compared with nonexposed infants. The study did not show an increased risk for severe retinopathy of prematurity for very low birth weight infants on sildenafil, and confirms results from a previous small singlecenter study of preterm infants born $<30$ weeks gestational age with bronchopulmonary dysplasia (BPD)-associated pulmonary hypertension $(\mathrm{PH}){ }^{2}$ Also, a study in a cohort of term and near-term newborns treated with sildenafil did not show an association with ocular complications. ${ }^{3}$

$\mathrm{BPD}$-associated $\mathrm{PH}$ is a common morbidity in extremely preterm infants. Two recent large prospective observational studies investigated late $\mathrm{PH}$ in the clinical course of preterm infants with evolving BPD. The incidence for BPD-associated PH was 11.7 and $14 \%$, respectively, and mortality in early infancy was high, reportedly 10.3 and $11.5 \%{ }^{4,5}$ An effective and safe treatment would obviously be desirable to decrease mortality and the burden for affected infants and their parents.

So what about efficacy of sildenafil in very preterm infants suffering from BPD-associated PH? Unfortunately, studies and data in this population are still very scarce. Nyp et al. reported retrospective data of 21 preterm infants with a median gestational age of 27 weeks who received sildenafil for BPD-associated $\mathrm{PH}$. Although they were able to show a reduction of pulmonary artery pressures (PAP) in their cohort, this did not translate into an improvement in pulmonary gas exchange or oxygen requirement. $^{6}$ Tan et al. recently reviewed 22 very preterm infants (median gestational age 25.6 weeks) receiving sildenafil for BPDassociated $\mathrm{PH}$ in their neonatal intensive-care unit. A decrease in PAP was demonstrated, and also a small but significant decrease in oxygen requirement from 0.57 to $0.42 .^{7}$ Similarly, Wardle et al. ${ }^{8}$ showed an effect of sildenafil on PAP in another case series of 14 extremely preterm infants. An earlier study addressed long-term follow-up over 2.5 years of 25 preterm and term infants with $\mathrm{PH}$ receiving sildenafil, and again an effect on hemodynamic parameters was demonstrated. ${ }^{9}$ Adverse effects were rare in all studies.

However, whether treatment with sildenafil reduces mortality or improves long-term outcome remains unknown. The above mentioned studies demonstrate that sildenafil is commonly prescribed in preterm infants, despite the well-known controversy about a previous Food and Drug Administration (FDA) warning regarding the use of sildenafil in children with $\mathrm{PH}$ following publication of the Barst trial. ${ }^{10}$ Surprisingly and also disappointingly, a search in a number of international trial registries did not reveal a single study currently registered with the aim to investigate the effect and safety of sildenafil in BPD-associated PH in preterm infants (www.clinicaltrials.gov, www.clinicaltrialsregister.eu, www. anzctr.org.au). We still do not know whether sildenafil is a therapeutic option for this specific population. Large prospective trials investigating the efficacy and safety of sildenafil in extremely preterm infants, addressing mortality and major morbidities are desperately needed before sildenafil can be safely recommended in this fragile population.

\section{CONFLICT OF INTEREST}

The author declares no conflict of interest.

\author{
K König \\ Children's Hospital Lucerne, Lucerne, Switzerland \\ E-mail: kaikonig@gmail.com
}

\section{REFERENCES}

1 Samiee-Zafarghandy S, van den Anker JN, Laughon MM, Clark RH, Smith PB, Hornik CP. Sildenafil and retinopathy of prematurity risk in very low birth weight infants. J Perinatol 2016; 36(2): 137-140.

2 Fang AY, Guy KJ, König K. The effect of sildenafil on retinopathy of prematurity in very preterm infants. J Perinatol 2013; 33: 218-221.

3 Kehat R, Bonsall DJ, North R, Connors B. Ocular findings of oral sildenafil use in term and near-term infants. J AAPOS 2010; 14: 159-162.

4 Mourani PM, Sontag MK, Younoszai A, Miller Jl, Kinsella JP, Baker CD et al. Early pulmonary vascular disease in preterm infants at risk for bronchopulmonary dysplasia. Am J Respir Crit Care Med 2015; 191: 87-95.

5 Bath R, Salas AA, Foster C, Carlo WA, Ambalvanan N. Prospective analysis of pulmonary hypertension in extremely low birth weight infants. Pediatrics 2012; 129: e682-e689.

6 Nyp M, Sandritter T, Poppinga N, Simon C, Truog WE. Sildenafil citrate, bronchopulmonary dysplasia and disordered pulmonary gas exchange, any benefits? J Perinatol 2012; 32: 64-69.

7 Tan K, Krishnamurthy MB, O'Heney JL, Paul E, Sehgal A. Sildenafil therapy in bronchopulmonary dysplasia-aaociated pulmonary hypertension: a retrospective study of efficacy and safety. Eur J Pediatr 2015; 174: 1109-1115.

8 Wardle AJ, Connolly GM, Stonier T, Tulloh R. Sildenafil in bronchopulmonary dysplasia—safe to use? Arch Dis Child Fetal Neonatal Ed 2015; 100: F369.

9 Mourani PM, Sontag MK, Ivy DD, Abman SH. Effects of long-term sildenafil treatment for pulmonary hypertension in infants with chronic lung disease. J Pediatr 2009; 154: 379-384, 384.e1-2.

10 Barst RJ, Ivy DD, Gaitan G, Szatmari A, Rudzinski A, Garcia AE et al. A randomized, double-blind, placebo-controlled, dose-ranging study of oral sildenafil citrate in treatment-naıve children with pulmonary arterial hypertension. Circulation 2012; 125: $324-334$ 